\title{
On Theory in Informal Logic
}

\author{
PERRY WEDDLE California State University, Sacramento
}

Imagine my title to contain two main concepts - "informal logic," and "theory of informal logic." Only at the end do I consider the flashier one, theory, and then mainly out of guilt. Mostly I become entangled in the idea of informal logic itself, in which lies the key to theory. In other words the paper turns out to be nine tenths what its author fancies to be ground clearing.

\section{I}

One ought to be struck by how recently the term "informal logic" has become current. As far as I can tell it appears in no widespread obvious formative source published more than a decade ago. It's not in Copi, not in Toulmin's The Uses of Argument, not in the English translation of The New Rhetoric, not in Hamblin, not in Kneale and Kneale, not in the Encyclopedia of Philosophy, not in the titles of anything in Blair and Johnson's extensive $1980 \mathrm{bi}$ bliography. Almost ready to attribute coinage to Johnson and Blair themselves, as in the titles of their newsletter and first Symposium, I stumbled upon the term in, of all places, my own textbook, which tome contains the phrase, "the subject sometimes called informal logic" - as if this were widespread usage. My misjudgement could have been built on at most wo instances, Carney and Scheer's bifurcation of logic in their 1964 textbook or, more likely, Gilbert Ryle's 1953 Tarner lecture, published in Dilemmas, a source which, as Ralph Pomeroy notices, gets neglected. That's 30 yearsnot, I hope, the anniversary of a word.[1]

The word comes naturally. We hear it and know what it means, or think we do and have for years. For the term embodies two distinctions which as teachers we make or have made. One of these comes during the inevitable firstweek "consumer" lecture in the traditional "global" logic course, the lecture which warns students that there will be some "mathematical" logic, yes, with formation, transformation and truth rules and all the rest, but also plenty of common sense logic done in natural language. The other distinction with which we feel comfortable delineates two basic ways to appraise bits of reasoning - either by virtue of logical form or else by virtue of what might be called "everything else."

Why fuss over words? Consider this passage from John McPeck's Critical Thinking and Education:

Informal logic... begins by distinguishing its enterprise from formal demonstration, which characterizes logic, geometry, mathematics and other formal sciences. In these latter areas, inferences are justified or prohibited by direct appeal to formal rules. But informal logic does not have the advantage of formal rules (hence the term "informal"), so that mistakes in reasoning and argument must be characterized by other, less precise means.[2]

We can see at work here the first of the two distinctions. Retrace the progression. "Informal logic" suggests notformal logic, which in turn suggests that logic is formal logic. Formal logic being mathematical logic, and such logic being precise, this suggest that informal logic is imprecise, or less precise; whereupon if informal logic is going to call itself logic then it had better be, or be like, formal logic. But it isn't. And if it were, then it would no longer be informal logic. 
It's the term, that is to say, which thrusts upon us a dichotomy which if accepted causes underplay of the subject's origins and possibly its best nature. The term inclines its hearers to consider the subject not according to what it is or should be but according to what it is not. From a perspective like McPeck's those who knock around in the subject of reasoning and its teaching can come to behave like social scientists presented with the model of physics-either manifesting guilt over dissimilarity of subject to model, or urging conformity of subject to model, or considering abandonment of subject all together.

That's one direction. Another results from taking "formal" not to mean mathematical logic, necessarily, but from taking "formal" according to the other distinction - in which it means "according to logical form." One result of such a reading I encountered recently on my own campus: "Weddle, you say that critical thinking (which my university now requires) really ought to be informal logic. And yet the syllabi of many instructors teaching the philosophy course you think should be approved use throughout what amounts to logical form. Some of the submitted sample exercises look like alphabet soup. That's not informal logic; that's formal logic." The inconsistency charge results from its author having construed a term. Had I not blundered by using it - had I used "reasoning" instead, or "argumentation" - then the alley which the term suggested would have been blocked. Even philosophers teaching or being forced to teach courses called informal logic, or called something else but interpreted to mean informal logic, may feel the pull to eschew logical structure. Were they to surrender that would be a shame, for logical structure in teaching reasoning is constantly useful. Every day one can do what Thomas Schwartz has recently suggested-reconstruct arguments as valid (including inductive ones, incidentally) and then evaluate the premises. [3] Or take fallacies: most of them display nicely either as invalid forms or as parasites upon valid forms. One can display equivocations as "p-thereforeq's," or as Four Terms, or as broken chains of hypotheticals. Even ignoratio elenchi is sometimes usefully taught as formal-as when a process of elimination plays off of a dilemma presenting fewer disjuncts than dictated by an appeal to real interests. This yields a form in which the eliminatees number two or more fewer than those in the true dilemma. The invalidity then stands out starkly. All sorts of opportunities exist, and by no means confined to the subject of fallacies. Use of logical form, in other words, ought not to be down-played in the teaching of reasoning just because the subject for whatever reasons happens to have come to be called informal logic.

In yet a third direction those words can lead, someone also construes "informal" to mean "lacking logical form," except that this time the result is the downgrading or elimination of the informal. In his preface to The Art of Logical Reasoning Schwartz comes close to taking such a direction. Informal approaches, he thinks,

trade logical rigor for of fhand applicability. Containing more informality than 10gic, they provide tools that are wanting in temper and sharpness. We expect well-educated people to construct and criticize pieces of reasoning with an uncommon degree of rigor, subtlety and precision-just the qualities that are downgraded by many informal logic texts. [4]

In their stead Schwartz provides a rather intriguing, nonsystematic, mainIy class logic, formal in the "logical form" sense of "formal". Although Schwartz complains here about existing informal treatments, about which he could be right, yet out with the same bathwater would go any improved potential member of their ilk. As with McPeck, words like "precision" and "rigor" become reserved for the Right Stuff and, accordingly, denied to others.

Something, then, had better be said about the imprecision charge. The term 
"informal logic" suggests that formal logic and informal logic are comparable enterprises; whereupon, weighed in the balance, one of them is found wanting. This is puzzling. Is model railroading more precise than railroading? What could that mean? The former boasts interminable hairsplitting disputes over various locomotive drive-wheel configurations, the latter boasts batteries of executives, lawyers, computers and accountants. On the matter of precision, model railroading and railroading simply aren't helpfully compared: To claim enterprise $\mathbf{x}$ more precise than enterprise $\mathbf{y}, \mathbf{x}$ and $\mathbf{y}$ would have to be doing similar things. And it has yet to be established that formal logic and informal logic do or ought to do similar things.

In both McPeck and Schwartz "imprecise" seems to refer to methods. What would it mean to say that one method were more precise than another? One wants to ask, "Precise at what?" Put to a task to which it is illsuited any method can look bad. Schwartz speaks of sharp tools. Tools for what? The business end of a corkscrew had better be sharp, the sharper the better; but for the gizmo one uses to pit cherries, the sharper the worse. Until it has been established that formal and informal logic employ comparable methods, comparisons with respect to precision won't be helpful.

Now if the word "informal" can lead to neglect of what could be the subject's best nature, so can the word "logic." Here's McPeck again:

... if something is truly informal (that is has no detachment rules) then it is not logical in the normal sense of the word. The term "logic," then, neither explains the meaning of informal logic nor distinguishes it from rhetoric. [5]

For those pursuing what they had imagined to be informal logic this presents a Hobson's choice: Either continue but quit calling the enterprise logic, or else get systematic, formally speaking, in which case quit calling the enterprise informal.
In this reasoning I want to check out two main assumptions - that whatever were called informal logic would have to be a branch of logic, and that whatever is called informal logic could not be a branch of logic. The contention that informal logic must be a branch of logic rests on the unstated general hypothesis that any discipline with a compound name carries with it the baggage entailed by the name's constituent words. The hypothesis is questionable, rendering arguments which tap it, which proceed from constituent-term baggage to entire-term baggage, into what many of us teach under the heading "Composition." (According to the hypothesis the subjects Home Economics would have to be economics, Canadian Government government or Criminal Justice justice.) Although l'll argue presently that as practitioners of informal logic we are already a branch of logic, why should it matter whether we're a branch of logic? Suppose for political or intellectual reasons we and our descendants were to join or to merge with, say, rhetoric departments, to participate in Rhetoric Association meetings and publish in rhetoric journals, all the while retaining the title informal logic. We would have become a branch of rhetoric. Such results may or may not be desirable, but not because of a constituent term in our subject's title.

The second main assumption is that something called informal logic could not be a branch of logic, an assumption which rests on the contention that only systematic formal logic is logic. And though the contention may carry some persuasive force, descriptively it's false. From about the 13th Century to, let's say, World War II, when the ideas of the great mathematical logicians finally became dominant, Aristotle's Organon (plus or minus sundry accretions, deletions and alterations) virtually circumscribed the subject of logic. Supposing that one could divide the six diverse treatises collected into the Organon into "formal" and "informal" components - supposing, that is, that one could so divide what until just yes- 
terday passed as logic - then by most measures the "informal" stuff would exceed the "formal." Accordingly, in the 'til recently received sense of "logic," something need not have been formal in order to qualify as logic. Indeed in McPeck's sense of "logic" there would have been no logic until Frege. As direct descendants of the author of the Organon informal logic practitioners bear family resemblances to those who practice formal logic. Or, one could as well say, those who practice formal logic bear family resemblances to practitioners of the informal.

\section{II}

"What is the role of theory in informal logic?" Although so far l've indicated a few things which the subject need not be, answers to the question await an understanding of what the subject ought to be. Although such an understanding I have not got, I have inklings.

Suppose a hundred astute, highlyeducated people a decade or more out of school, people used to dealing with argumentation and evidence in their professions and daily lives. They're each given two voluminous empty files, one marked "GOOD REASONING," the other marked "BAD REASONING." Every day for a year they photocopy or summarize one example for each file, including a phrase or few sentences in comment. Into one file goes material which the subjects admire or would be pleased to have done themselves; into the other goes what they would avoid and about which they would want to warn others. At the end of a year each person distills his or her file down to ten prime examples. About the distillate let me speculate. On the GOOD side would be such maneuvers as a case built on a perhapsnot-quite-perfect comparison, but one which recasts its subject in an entirely new light. Probably we'd find a wellwrought reductio which turns tables on an influential position. There would be problems solved by the unearthing of needed facts by employment of tech- niques so simple that a child could have thought of them, though until then no person had. Undoubtedly there would be the other sorts of case, too-cases which required less imagination than they did uncommon relentlessness at book-, leg-, or eyework. There would appear a few "copernican-type" solutions which by effecting a change of aspect transform a problematic $x$ into $a$ less- or unproblematic $y$.

In the other files would be found cases inadequately supporting conclusions but especially conclusions widely expected to be true. There would be pieces for which the overall descriptors would be words and phrases like "gobbledegook," "misses the whole point," "overkill," "tunnel vision," "cheap shot," "doesn't see that it cuts both ways," "Pollyanna mentality," "pure propaganda," "oversimplifies," "naive," "emotional," "coincidence," "begs the real issue," "sloppy," "mountain out of a molehill," "Strangelovian," "byzantine," and "exaggerated." Relative to the descriptors we learned in intro logic ("valid," "sound," "accident," "Existential Instantiation," "concomitant variation" and all the rest) the descriptors of the argumentation in the files will be "infected with values." Prominent will be viewpoints, intentions, anger and admiration; concern about a result's good or harm; considerations of rarity; attention to power, personality and progress.

Now suppose that the findings of my elite Hypothetical Hundred were to represent a kind of standard of what the evaluation of reasoning really is, a standard toward which we would like our students to strive. The supposition seems not unrealistic. The standard would indicate or remind that the evaluation of reasoning carries with it an integral moral component. ("Moral" here in the psychological sense-pertaining to human actions and attitudes.) Furthermore, the findings would indicate that reasoning's descriptors are integrally pedagogical-conveyors of warnings, lessons and ideals. If real reasoning processes are supposed to 
get us from where we are or think we are, to where we want to be or think we want to be, and also to question where we think we are and think we want to be, as well as to question the reliability and efficiency of the routes, then reasoning, its description and evaluation will necessarily be very human. Whereas traditional logic worried less about the point than about rules, what in reasoning we truly admire or fear, trust or scorn, has less to do with rules than with the point. Somewhere in all this I sense a subject lurking. If for historical reasons it must be called informal logic, well so be it.

Has the deck been stacked? I can't see how. Many of the descriptors in the pair of lists could apply equally to a piece of art criticism, to a laboratory demonstration and to a mathematical proof. Nor has the choice of adjectives "good" and "bad" infected the result, the difference between description and evaluation in this context being nebulous if not illusory. For example, there would be no hesitation into which file to throw an invalid proof, or an experimental result built on faked data. (Objectivity and scorn are not incompatible, nor are objectivity and praise.)

Supposing the picture just sketched to express a measure of reality, that humanity and pedagogy are essential to the arts of reasoning and its evaluation, this would by no means entail that those arts would not improve if subjected to systematization like what has already improved innumerable subcategory of reasoning. The term "informal logic" should not constrain us from going in formal directions if they seem the best ways to go. Possibly a truly massive mobilization of intellect in the service of formal semantics and pragmatics would accomplish something worthwhile. Frankly I doubt it, not because I fathom the power of formalizing tools in the hands of our best creative logicians, but because I fancy that I fathom the enormity of the task, the value of rival methods, and especially the abilities of those who desperately need results now. My doubts may be summarized under two themes: that systematization would encounter such obstacles that it would prove to be more hindrance than help, and that since the drive toward systematization constitutes less a result of investigation than a requirement, we would do well to examine what's behind the requirement.

First the alleged obstacles. From our stock in trade consider just one member of a very long list, the matter of participants. Is this (albeit simple-minded) argument any good?

\section{Are interior decorators really necessary? Yes, but not for the accepted reasons. Since one cannot set one's own broken leg one relies on a doctor. Without a formidable knowledge of legal intricacies one consults a lawyer. Likewise, unless one is well versed in the home furnishing field the services of an interior decorator are a distinct advantage.}

Not only analogical strength here-but also what the very argument itself is depends on who is being addressed. Were the addressees ordinary folks thinking about redecorating their living rooms then the argument would be one thing and its analogy weak. (Serious medical trouble and serious tax or criminal trouble typically attend do-ityourself doctoring or lawyering. But besides a reputation for zany, quirky, cheapie, or tacky taste-by no means a liability - what trouble attends do-ityourself home decorating?) On the other hand suppose the addressees instead to be up-and-coming business types who do lots of business-related entertaining at home. The argument would become something else again. Its analogical strength would soar with the stakes. And of course one can imagine an indefinite multiplicity of audiences or argument moves for those same words. How could such a multiplicity be recursively enumerable without a lot of intuitive decision-making of the very sort which systematization would like to minimize if not eliminate, the very sort of stuff which, in order to assess the argument informally, one must likewise appreciate and decide on? So what's the advantage of the systematic procedure? 
A similar multiplicity attends roles of arguers. A student assigned her Freshman Composition weekly essay, this one on whether to ban handguns, can scarcely be accused of having left gaps in her case because it lacks details from this quarter's FBI Uniform Crime Statistics. Relative to her status, the 1,000-word limit, and the week she had, her production is splendid. The piece in last Sunday's paper, on the other hand, by someone who teaches and writes on criminology for a living would, without those statistics, be seriously flawed.

At the risk of committing Howard Kahane's fallacy "Small Sample" let me speculate on the enormity of the systematizer's task. The sorts of decisions one must make about matters concerning participants, on which 1 touched on only the tiniest fraction, typify countless others. To evaluate and construct reasoning intelligently one must constantly decide such matters as what and how large the assumptions are; where the burden of proof lies; whether there's an argument there at all; what, and how strong, counterarguments would be; where the case begins and ends; what sort of hedge the conclusion should have when the premises are nonmathematical or vague probabilities; what evaluation standard to use; when it's fair to demand more facts; how closely an analogy fits; whether there's a genuine question; whether it's begged; to what extent something in someone's pastsuch as an economics Ph.D., or a Chappaquiddick - counts for or against. This list with no effort could be dou bled, and doubled again. However large the systematizer's task be imagined, the act of imagination itself seems to suggest further orders of task. If the system were to be better than alternatives it would have to accommodate better than they all sorts of human considerations, the sorts of thing admired and scorned, and taken into account, by my Hypothetical Hundred. And supposing a system could be made to evolve. Using it would itself require so much very intuitive decision-making that instead of trying to crank the mechanism up it would be easier and more reliable to forgo the ride and to hoof it. And hoofing it here needn't be second best. Hoofing it has advantages of its own, one of which is that one gets used to hoofing it, hence better at the task

Earlier I spoke loosely about the desire for system, an overall theory, being less result than requirement. Whether by "system" one means something Euclidean-like, something Newtonian-like, something Linnaeanlike-or merely something a good deal more organized than what we've got at present-it's worth asking why it would be better if informal logic became more systematic, more theoretical.

One assumption seems to be that what marks a viable discipline is an overall theory. And for certain categories of endeavor the assumption about viability and theory is undoubted. ly correct, but not for all. I want to speculate briefly about the sorts of consideration which make theory worth having.

What would a "theory" look like, a theory not of something which resembles what some thinkers may have expected informal logic to be, namely imprecise mathematical logic, but a theory of something which less resembles a system of rules that it does a fundamental human activity. Please don't laugh; I suggest the prosaicthe art of driving a car

Suppose that I set about teaching my daughter to drive. Should I go to a "theory of driving?" What would one be? There is something called "Defensive Driving." Defensive driving is a strategy built on a theme-Think of trouble well before it happens, then avoid it. For psychological reasons that's a good theme, and a good slogan. But is it a theory? Fundamentally, "Defensive Driving" summarizes the same hodge-podge of rules-of-thumb which one would have taught without the slogan: Assume the other driver's blind or drunk, Don't tailgate, Don't drink, Don't fully trust your equip- 
ment, Maintain it conscientiously, Use your mirrors constantly, Carry flares, first-aid kit, ice-scraper... The slogan "Defensive Driving" nicely summarizes such countless rules-ofthumb, and by summarizing them perhaps adds to them. Heuristically. But it doesn't add to them theoretically, not as the Universal Gas Law, say, adds to Boyle's, Charles' and Gay-Lussac's laws, or as the Kinetic Theory of Gases adds to the Universal Gas Law. In the gas examples theory predominates, but not in the driving example

Defensive driving's flip-side also suggests something about so-called fallacy theory. What would a theory of traffic accidents look like? It would have to be extremely multiple-downright messy - in order to accommodate usefully the myriad causes of traffic accidents: all sorts of driver error; all sorts of manufacturer and maintenance error; all sorts of weather and road hazards, and so forth. One can see here, too, how very pedagogical a good informal logic "theory" would have to be. The quality of any categorizing of traffic accidents into kinds would become measured by its ability to effect prevention-which means explaining to somebody what to do.

Now none of this is to say that we would not do well to get more systematic, rigorous and precise-in our discipline's own terms. We could use more accurate and useful accounts of reasoning's fundamentals. We could stand consolidation of the gaggle of classification systems. All sorts of principles, no doubt, await discovery and refinement. We sorely need a body of literature in common

Now one can call Defensive Driving a theory if one wants. Usage poses no problem, nor even academic usage At my institution we have "Theory of Motor-Development," "Theories of Personality," "Theory of Dramatic Production," and so on.

Suppose something like the driving comparison, dignity aside, not wholly inappropriate. What would it suggest for us? Maybe that a theme does lurk out there around which to summarize what we do or ought to. Sometimes I catch myself being tempted by something like "Defensive Driving," something perhaps called "An Instrumental Model of Reason." Suitably packaged this mouthful could be promoted with the fanfare attending the offering of a beachful of condominiums

What, though, would "An Instrumental Model of Reason" look like? It would call attention to what we want to achieve (called "conclusions" or maybe "Volitional Realizations"), and to means to them (called "premises"). It would examine the relations between the two and if not pure hype would promote the arts of considering alleged ends as means, to be examined themselves. Fallacies would fall under the model perfectly - to be explored as promising but blind alleys on the paths to goals. And since the point of the model would be a reliable vehicle to truth, epistemic considerations would become many fold more prominent than before. The package almost seems promising. (Perhaps I'm beginning to believe my own rhetoric.)

But reasoning is already purposive, and since by far the bulk of the familiar reasoning techniques enshrined in the language are already means, to speak of an "Instrumental Model" would, like "Defensive Driving," just be a way to package what we know already. And it's of course all been done before. Alexander of Aphrodisias, or whoever it was who promoted six diverse treatises as a "package" under the title Organon, "the instrument," beat me to it by a millenium or two. The moral is clear: If you're gonna sell reasoning or real estate, better not try to be first.

\section{Notes}

\section{[1] See the References}

[2] John E. McPeck, Critical Thinking and Education, New York: St Martin's, 1981, p. 68. Slightly altered, the original having a 
double subject, "logic and rhetoric," which along with plural pronouns, etc., I simplified.

[3] Thomas Schwartz, The Art of Logical Reasoning, New York: Random House, 1980, p. 12.

[4] Ibid., p. viii.

[5] Op. cit., p. 69.

\section{References}

J. Anthony Blair and Ralph $\mathrm{H}$. Johnson, Informal Logic Newsletter, Windsor, Ontario, vol. 1, no. 1, July, 1978

James D. Carney and Richard $K$. Scheer, Fundamentals of Logic, New York: Macmillan, 1980, 3rd edn. Irving $M$. Copi, Introduction to Logic. New York: Macmillan, 1982, 5th edn. Paul Edwards (ed.), The Encyclopedia of Philosophy. New York: Macmillan, 1967.

C. L. Hamblin, Fallacies, London: Methuen, 1970.
Ralph $H$. Johnson and J. Anthony Blair, "A Bibliography of Recent Work in Informal Logic" in Blair and Johnson (eds.), Informal Logic: The First International Symposium, Pt. Reyes, CA: Edgepress, 1980.

William C. Kneale and Martha Kneale, The Development of Logic, Oxford University Press, 1962.

Ch. Perelman and L. Olbrechts-Tyteca, The New Rhetoric: A Treatise on Argumentation, Notre Dame: University of Notre Dame Press, 1969

Ralph S. Pomeroy, "Ryle On (And For) Informal Logic," Informal Logic Newsletter, vol. v, no. 1 (Dec. 1982), pp. 23-25.

Gilbert Ryle, "Formal and Informal Logic" in Dilemmas, London: Cambridge Univ. Press, 1956.

Stephen Toulmin, The Uses of Argument, Cambridge: Cambridge Univ. Press, 1958.

Perry Weddle, Argument: A Guide to Critical Thinking, New York: McGraw-Hill, 1978.

Perry Weddle, 2511 Q Street, Sacramento, CA 95816 